\title{
Agôn
}

Revue des arts de la scène

Critiques | Saison 2014-2015

\section{Straight White Men de Young Jean Lee}

La Norme dans la peau

\section{Marion Siéfert}

\section{OpenEdition}

Journals

Édition électronique

URL : http://journals.openedition.org/agon/3126

DOI : 10.4000/agon.3126

ISSN : 1961-8581

Éditeur

Association Agôn

Référence électronique

Marion Siéfert, «Straight White Men de Young Jean Lee », Agôn [En ligne], Critiques, mis en ligne le 01 novembre 2014, consulté le 23 septembre 2020. URL : http://journals.openedition.org/agon/3126 ;

DOI : https://doi.org/10.4000/agon.3126

Ce document a été généré automatiquement le 23 septembre 2020.

Association Agôn et les auteurs des articles 


\title{
Straight White Men de Young Jean Lee
}

La Norme dans la peau

\author{
Marion Siéfert
}

\section{RÉFÉRENCE}

Straight White Men de Young Jean Lee

Présenté du 16 au 19 octobre 2014 au Centre Pompidou, lors de l'édition 2014 du

Festival d'Automne à Paris

1 Avec Straight White Men que l'on pouvait découvrir au Centre Pompidou dans le cadre du Festival d'Automne à Paris, la dramaturge et metteure en scène Young Jean Lee poursuit son exploration des identités qui structurent la société américaine. Après The Shipment, spectacle hybride mettant en scène les stéréotypes qui affectent la communauté noire aux Etats-Unis, et Untitled Feminist Show, puissante et réjouissante démonstration de la plasticité et de l'hétérogénéité des corps féminins, Straight White Men s'attaque à ce qu'on appelle le " privilège » aux Etats-Unis, c'est-à-dire à la norme dominante masculine, blanche et hétérosexuelle, et à son mode de représentation traditionnel, le drame naturaliste en trois actes. Les codes qu'utilise Young Jean Lee sont on ne peut plus conformistes : un décor réaliste qui reproduit fidèlement la pièce à vivre d'un intérieur américain moyen, des personnages crédibles et une intrigue vraisemblable. Unité d'action, de temps, de lieu. Avec cette provocation formelle, la dramaturge new-yorkaise entend mettre à l'épreuve un modèle dominant en expérimentant les limites mêmes du genre dans lequel il est roi.

2 Young Jean Lee excelle dans l'observation des corps, persuadée que ce sont eux qui, avant tout, vont révéler les idéologies qui les habitent. Straight White Men est jouissif dans ce répertoire quasi exhaustif des gestes, remarques, postures, blagues et commentaires de l'homme blanc hétérosexuel, que la dramaturge-metteure en scène décline à travers les personnalités de ses quatre personnages. Son inventaire vaut comme démonstration. Jamais son effort acharné de description ne bascule dans la satire. Là est la force de la critique adressée par Young Jean Lee à ces hommes investis 
de leurs privilèges : chaque scène est peuplée par ces attitudes et ces gestes - autant de signaux presque imperceptibles - qui, cependant, conditionnent et façonnent les rapports de pouvoir dans la société. La façon dont ces hommes jouent au jeu vidéo, leur manière de se charrier, de lancer une blague sur les homosexuels, de plaisanter sur leurs modes de vie de "connards" de privilégiés pour ensuite se sentir brutalement offensés quand un des frères éclate en sanglots au milieu du repas de Noël, de danser en expulsant quelques pulsions mal canalisées, de jouer au Ku Klux Klan, de s'asseoir dans le canapé et de parler fort : toutes ces manières d'être révèlent les normes sociales et les valeurs avec lesquelles ces hommes - et avec eux, une grande partie de la société américaine et occidentale - structurent leur monde.

\section{Straight White Men}

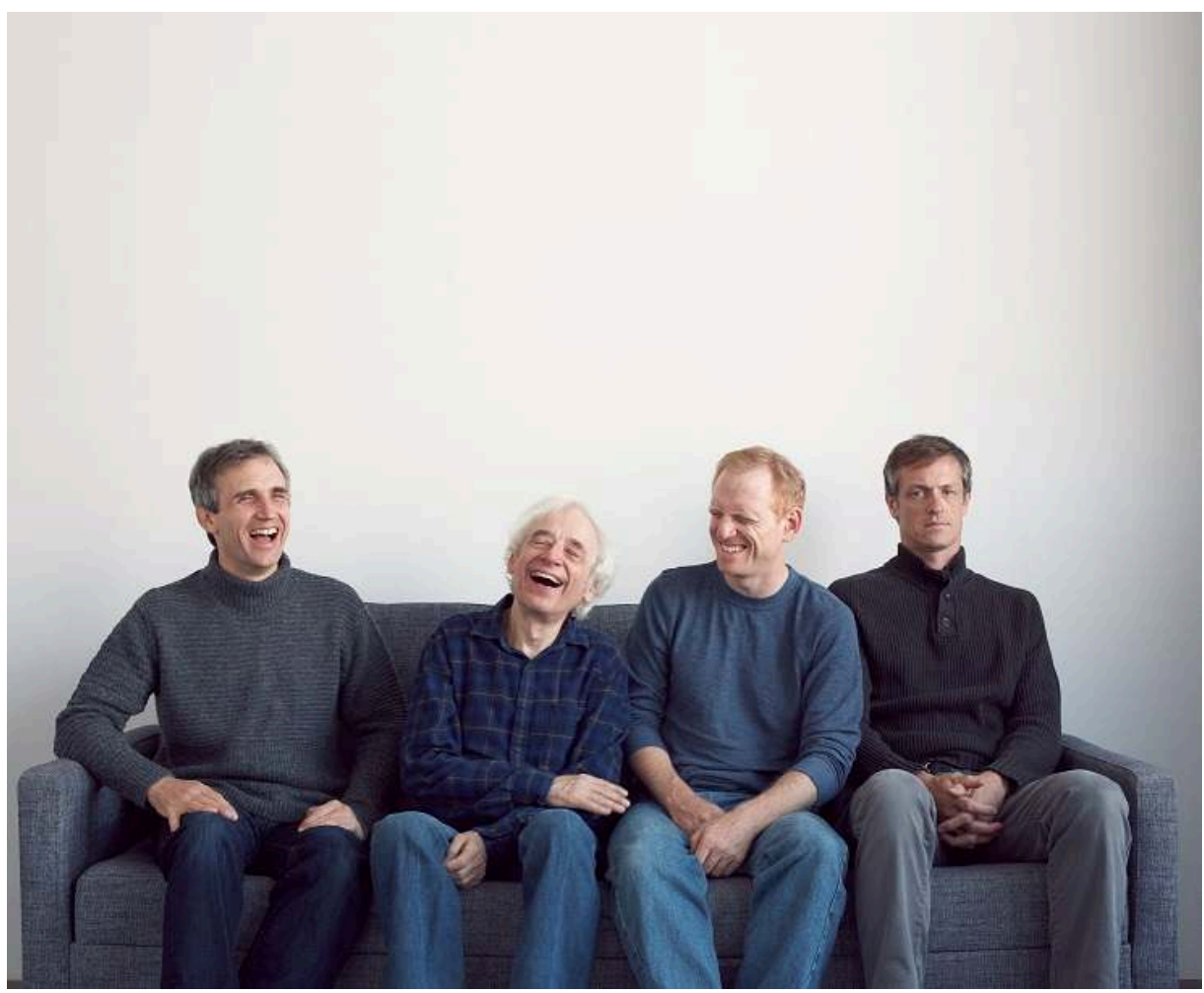

Mais si dans Untitled Feminist Show, la place fascinante que Young Jean Lee laissait aux corps révélait sa confiance en leur capacité à déborder des cadres qu'on leur assigne, Straight White Men se contente de citer et d'incarner des habitus, sans tirer pleinement parti du potentiel explosif de ces corps lâchés dans l'espace de liberté du théâtre. La convention du drame prend le pas sur les énergies qui cohabitent sur scène et ne laisse jamais les situations dégénérer. Tout se passe comme si le moule de la mise en scène sclérosait l'invention et contraignait, petit à petit, l'insolence à se plier à l'histoire. On assiste alors à l'acharnement d'un père et de ses deux fils contre le troisième qui, mystérieusement, refuse de régler son existence sur les valeurs individualistes et entrepreneuriales de la société néo-libérale. Même si la pièce de Young Jean Lee a la finesse de ne pas donner une cause à ce refus et ainsi, de se soustraire aux logiques explicatives des drames traditionnels, Straight White Men perd de sa souplesse provocante en essayant de maintenir à tout prix un idéal de vraisemblance et de cohérence dramatique. En voulant affronter absolument l'homme privilégié sur son terrain esthétique, Young Jean Lee réalise un coup de maître mais néglige ses propres 
armes théâtrales. Dans Straight White Men, nos perceptions sont trop rodées pour ébranler nos certitudes.

- À lire aussi sur Agôn, la critique sur Entitled feminist show 